\title{
Arctic Environment Preservation through Grounding Avoidance
}

\section{R. Glenn Wright}

Safe and Sustainable Shipping in a Changing Arctic Environmment ShipArc 2015

\author{
WMU - Malmö, Sweden
}




\section{Arctic Environment Preservation through Grounding Avoidance}

\section{Groundings are one of the most likely causes of ship casualties and causes of pollution.}

$\underline{\text { Topics }}$

- The Arctic Region

- Vessel Groundings

- Special Navigation Considerations in the Arctic

- Enhanced Environmental Situational Awareness

- Grounding Avoidance Strategies

R. Glenn Wright

p1301@wmu.se glenn@gmatek.com
Dr.-Ing. Michael Baldauf mbf@wmu.se 


\section{Vessel Groundings in the Arctic}

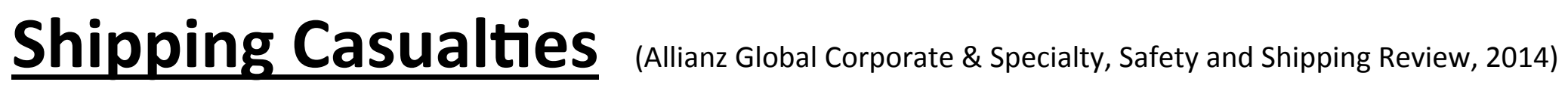

- 2002-2007: 7 (total)

- 2009-2013: 45 per year (average)

- Groundings one of most frequent of shipping casualties

\section{Total Losses}

- Increasing Loss Rates Environmental Impact

- Oil/Chemical Spills

- Container Losses

- Cost of Remediation

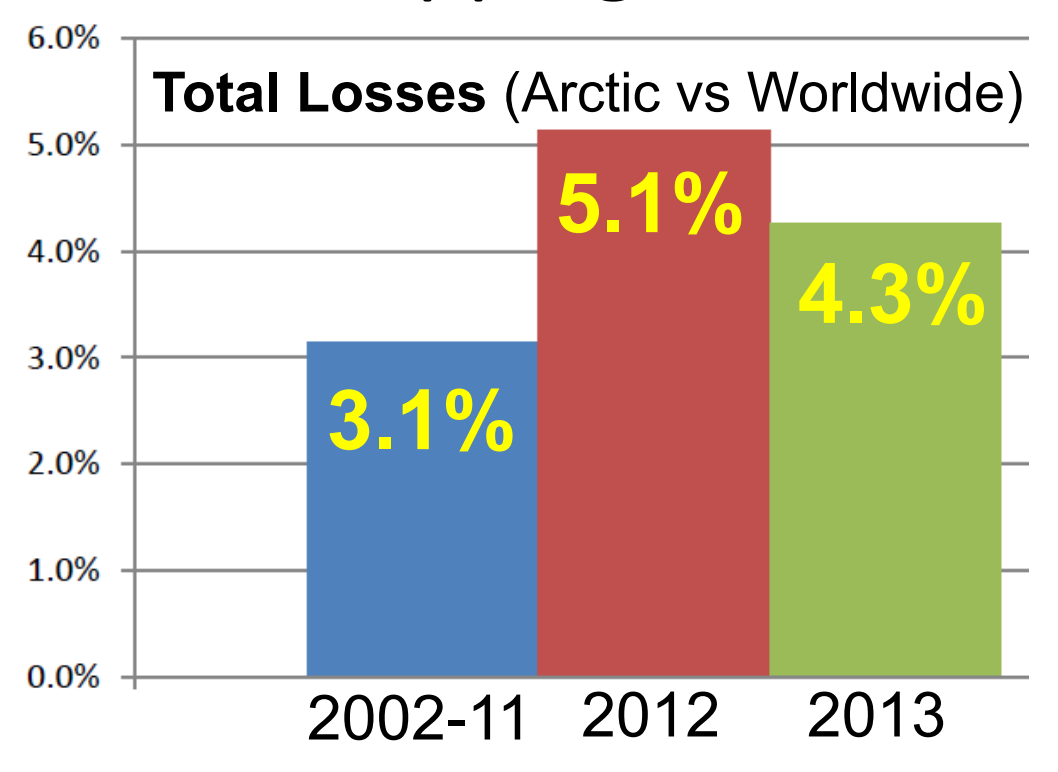




\section{Special Navigation Considerations}

Factors that make Arctic Navigation Difficult

- Lack of Physical Aids to Navigation (e.g., Buoys)

- Lack of Hydrographic Surveys / Inaccurate Nautical Charts

- Electronic Chart Display and Information Systems (ECDIS)

- Communications

- Environmental Sensing

- Potential for Terrorism 


\section{Special Navigation Considerations Physical Aids to Navigation (after the Winter thaw)}




\section{Special Navigation Considerations}

\section{Lack of Hydrographic Survey / Inaccurate Nautical Charts}
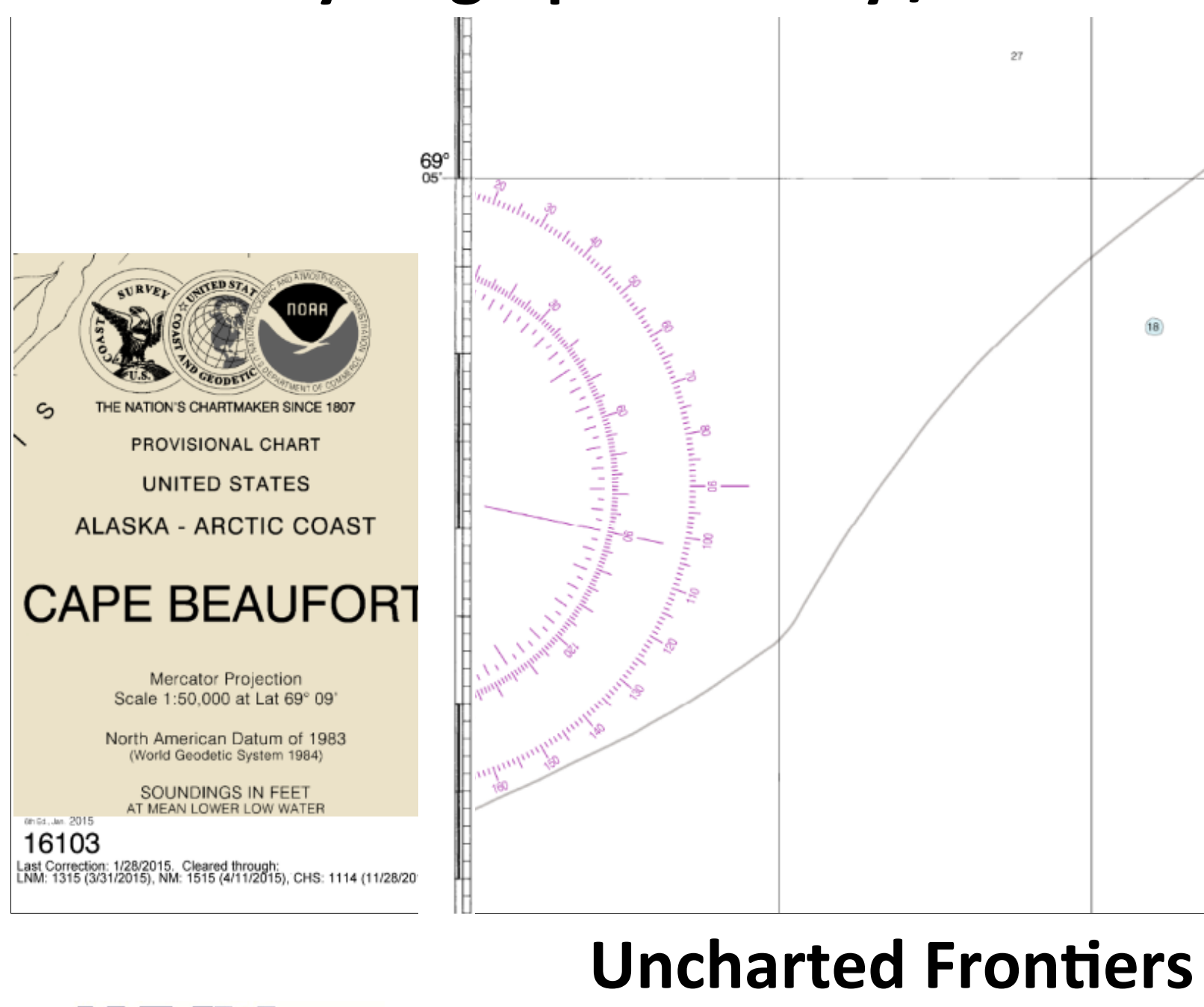


\section{Special Navigation Considerations}

\section{Lack of Hydrographic Survey / Inaccurate Nautical Charts}

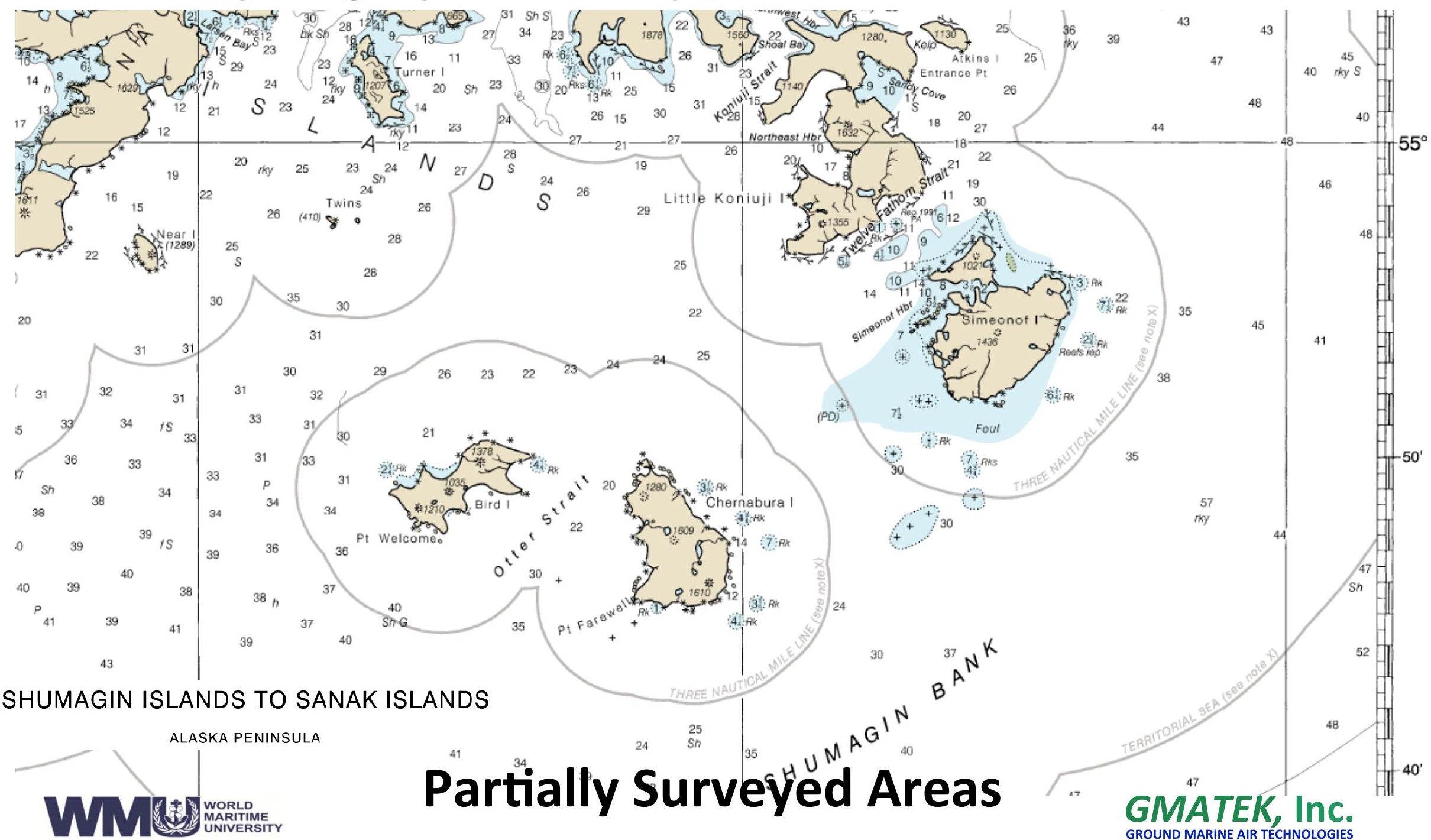




\section{Special Navigation Considerations}

\section{Lack of Hydrographic Survey / Inaccurate Nautical Charts}

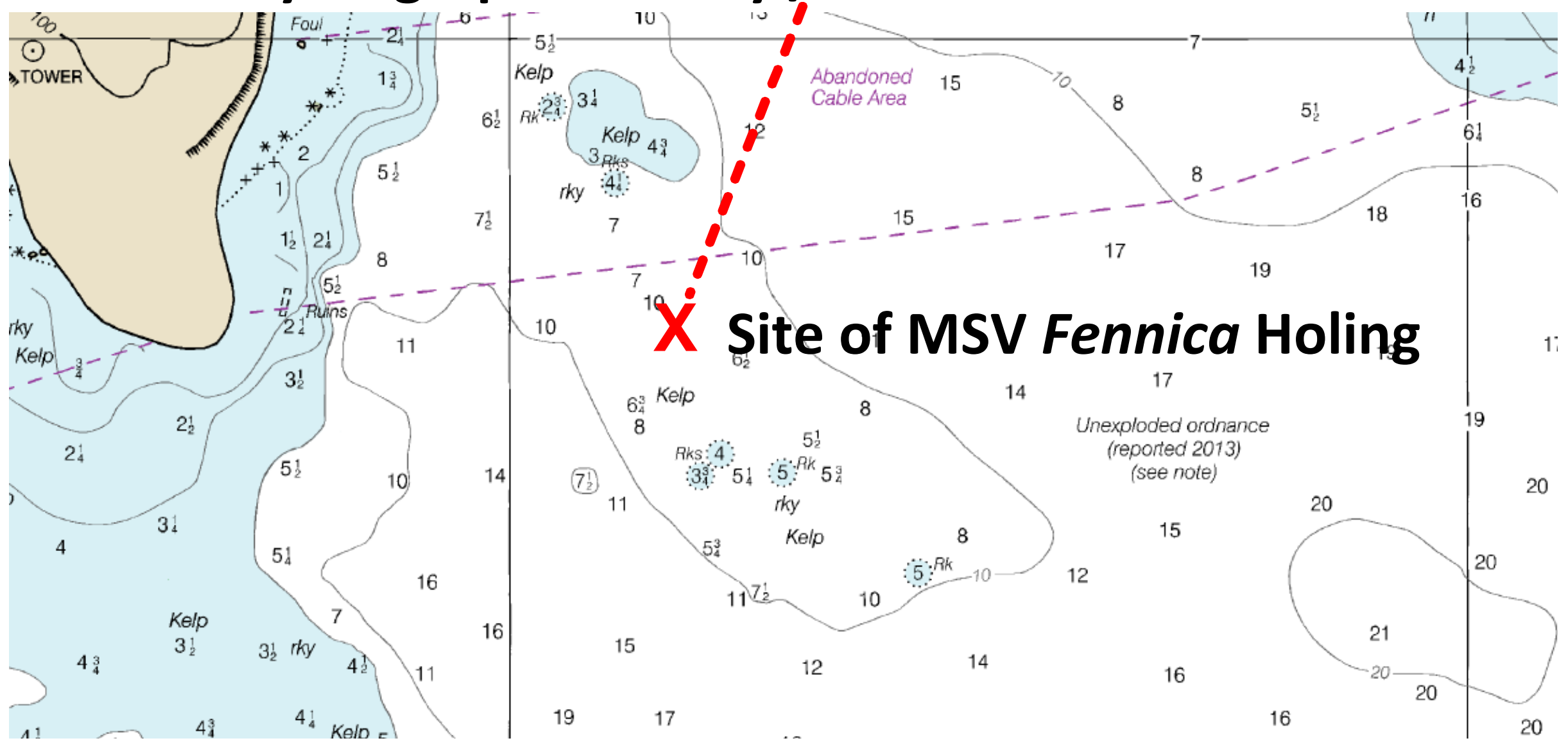

Areas that appear to be Well Surveyed 


\section{Special Navigation Considerations}

Electronic Chart Display and Information System (ECDIS)

- Category of Zone of Confidence (CATZOC) Rating (IHO S-57) Assurance that ENC data meets minimum depth and position accuracy

Most Arctic ENC do not have a CATZOC rating.

- If ENC have no Soundings Data, ECDIS is Useless.

- ECDIS Safety Contour and Depth Alarms may be Unreliable.

\section{Communications}

- Long Distances Favor Satellite and HF Communications. Both can be unreliable in the Artic.

- GNSS Unreliability / Lack of Maritime Safety Information. 


\section{Special Navigation Considerations}

\section{Environmental Sensing}

- Lack of Geographic Features/Buoys for Radar Navigation

-Echo Sounder: Depth below the keel - and Nowhere Else

Potential for Terrorism

- Global Navigation Satellite System (GNSS) and

Automatic Identification System (AIS)

- Denial of Service Attacks

- Spoofing (Taking control of a GNSS/AIS receiver) 


\section{A Short Summary of Your Situation while Navigating in the Arctic...}

1. Your GNSS may not provide you with reliable position information,

2. There are few, if any, physical features or buoys you can use to navigate using Radar,

3. Even if you know your position, your chart is unreliable and may even be blank,

4. You probably know the depth of the water below the keel (but even Columbus and Magellan knew that using a leaded line), and

5. Someone may purposely be trying to mislead you! ... a possible solution 


\section{Enhanced Environmental Situational Awareness}

\section{WMU Research:}

\section{Ship-Centric, Dynamic Virtual Aids to Navigation}

This research is intended to assist and improve vessel navigation in uncharted and poorly charted geographic regions, and in locations where physical aids to navigation do not exist and/or placement is not possible:

-The Arctic and remote locations,

- Tropical regions amongst coral reefs,

-Natural disaster and war zones... 


\section{Enhanced Environmental Situational Awareness}

\section{Advanced Technology}

- Forward-Looking Sonar

- Provides Real-time Visualization to 1,000m Forward the Bow

- Detects (Charted and Uncharted) Rocks, Ledges and Reefs

- Detects In-Water Hazards to Navigation

- Virtual electronic Aids to Navigation (VAtoN)

- Supplement existing Physical AtoN

- Can be placed where Physical AtoN and AIS-based VAtoN Cannot

- Not subject to AIS-AtoN infrastructure / VHF Radio Range Limits

- Georeferencing

- Navigation using Bearings to Sea Bottom Topography

- Provides Independent Means to Verify VAtoN Placement WNatReliant upon GNSS / Not Subject to GNSS Limitatipns $K$, Inc. 


\section{Enhanced Environmental Situational Awareness}

Forward-Looking Sonar
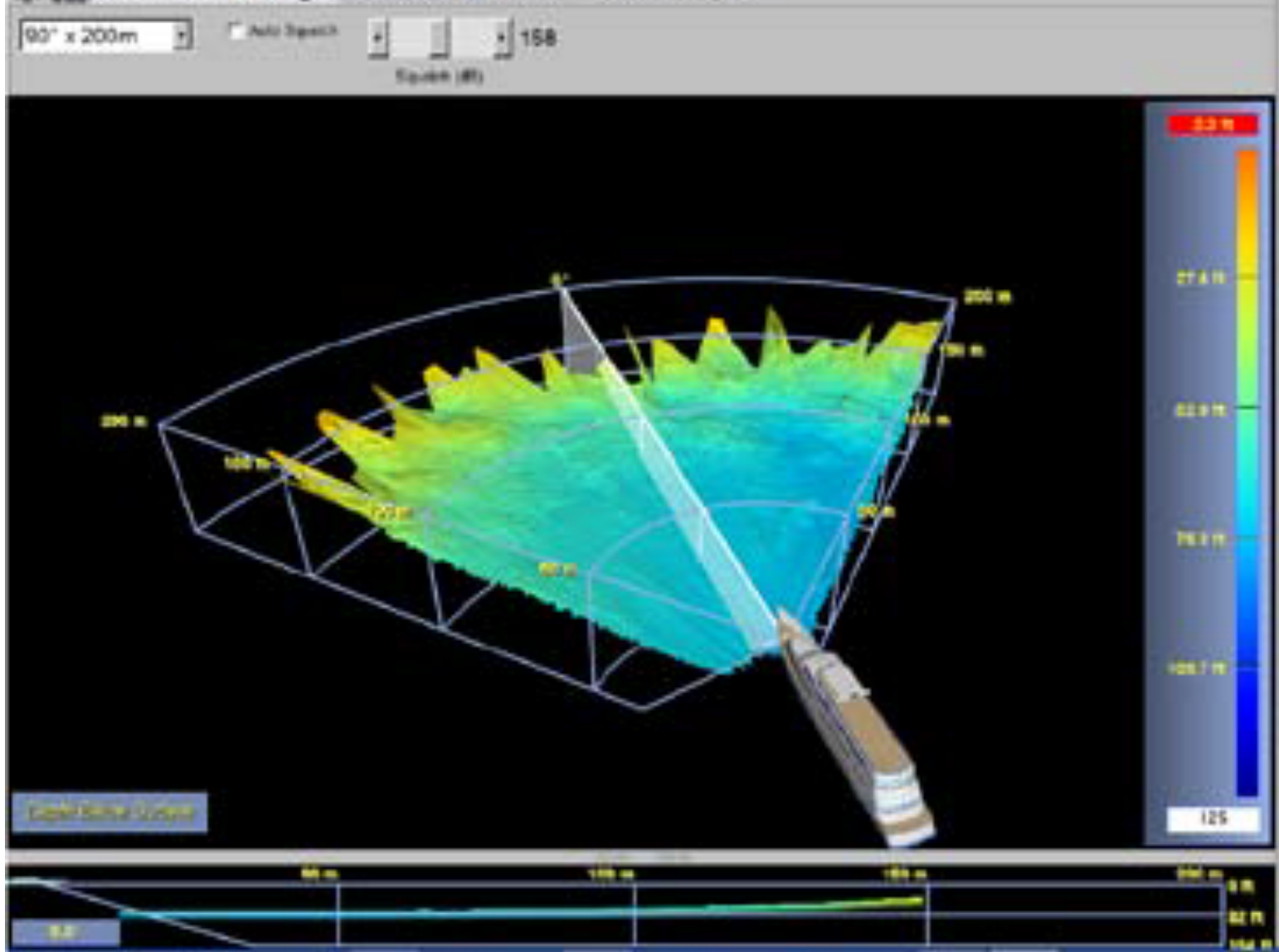

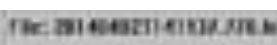

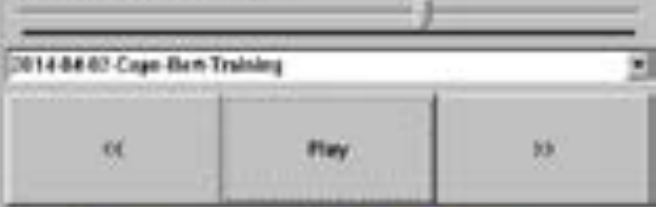

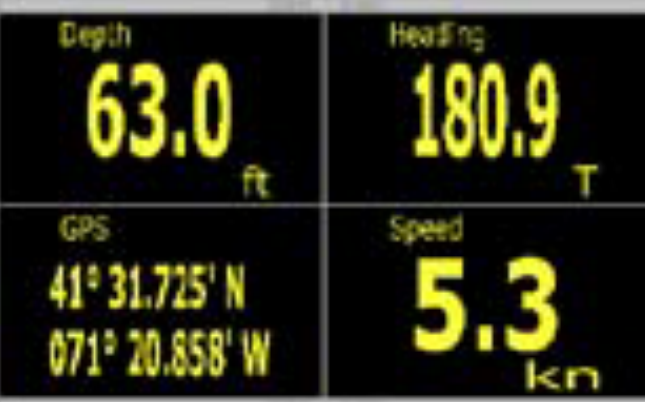

- Visualize Bottom Topography in Real Time to 1,000 m. - Detection of Reefs, Ledges and Hazards to Navigation.

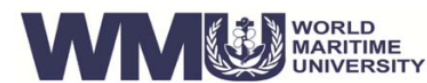




\section{Enhanced Environmental Situational Awareness}

VAtoN Placement on ENC/ECDIS

VAtoN are placed using soundings in accordance with U.S. Aids to Navigation System.

- Lateral • Information

- Non-Lateral • Special

- Regulatory

IALA-A and IALA-B Supported.

VAtoN can be dynamic based on physical vessel characteristics and requirements.

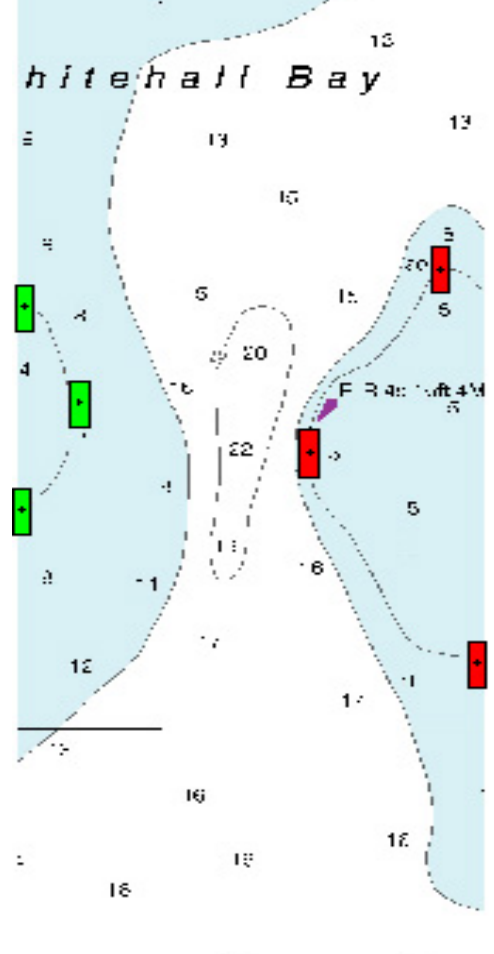

hitehati

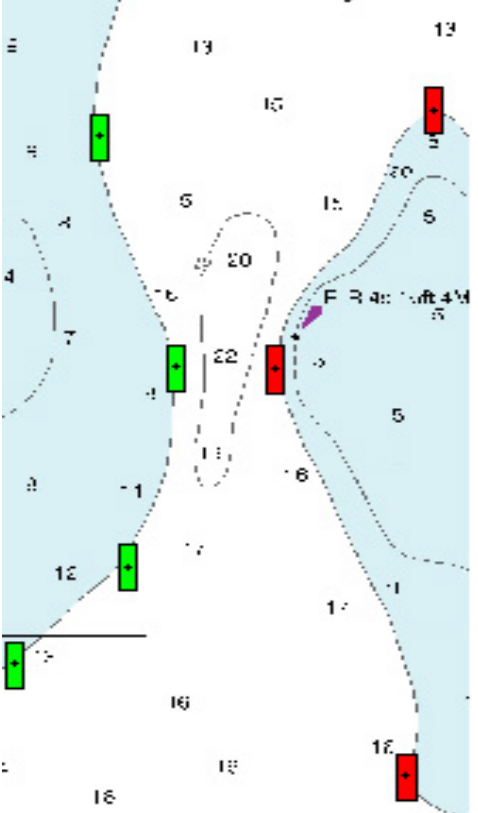

15

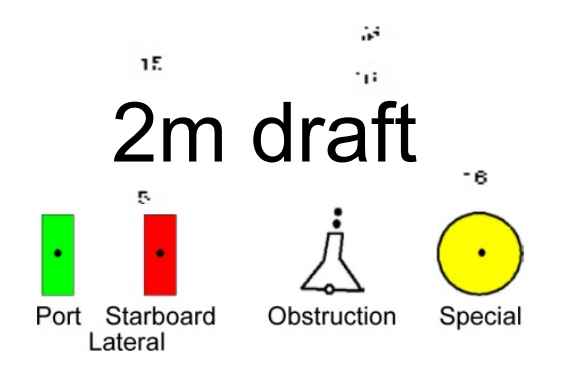




\section{Enhanced Environmental Situational Awareness Georeferencing to Bottom Topology}

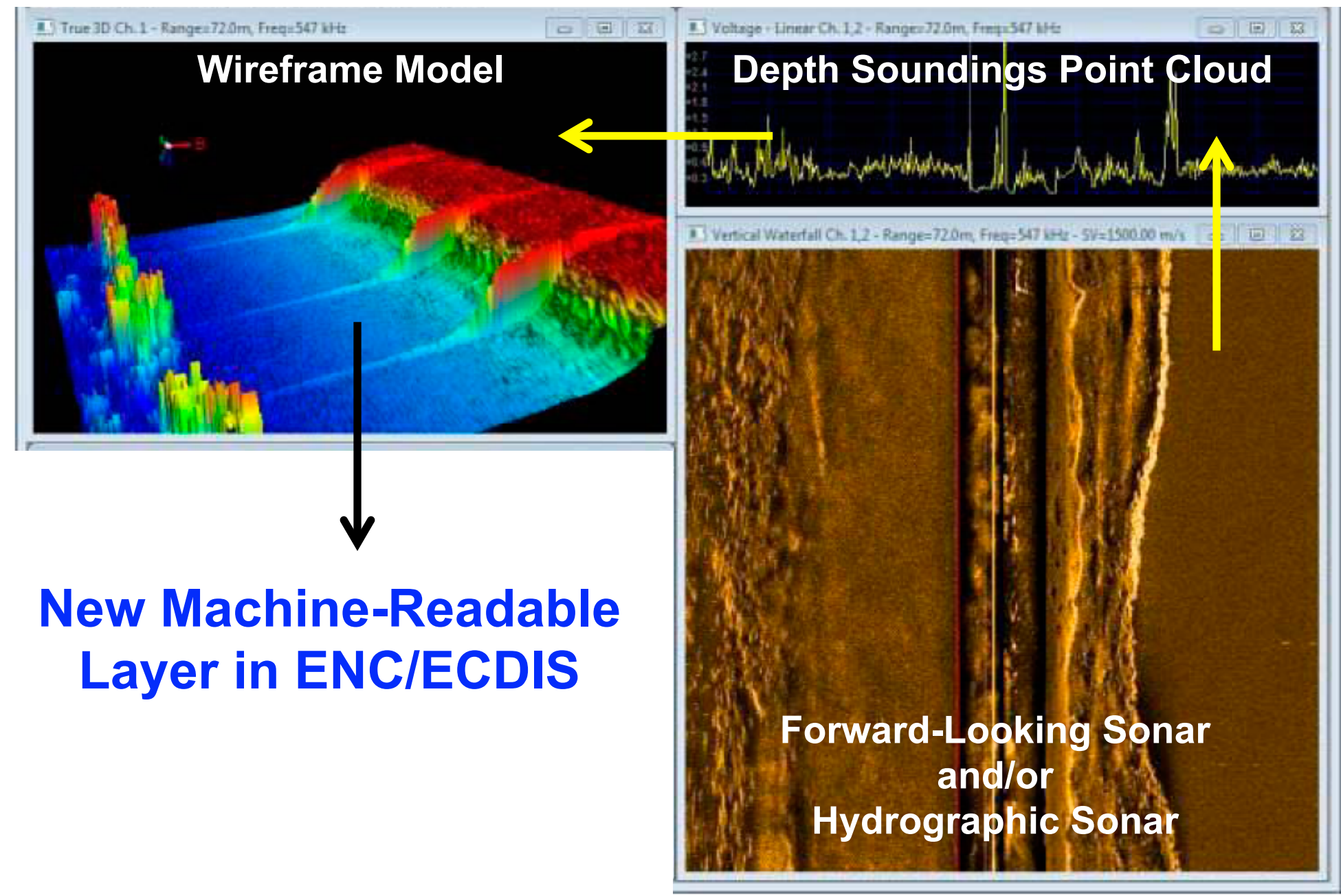




\section{Grounding Avoidance Strategies}

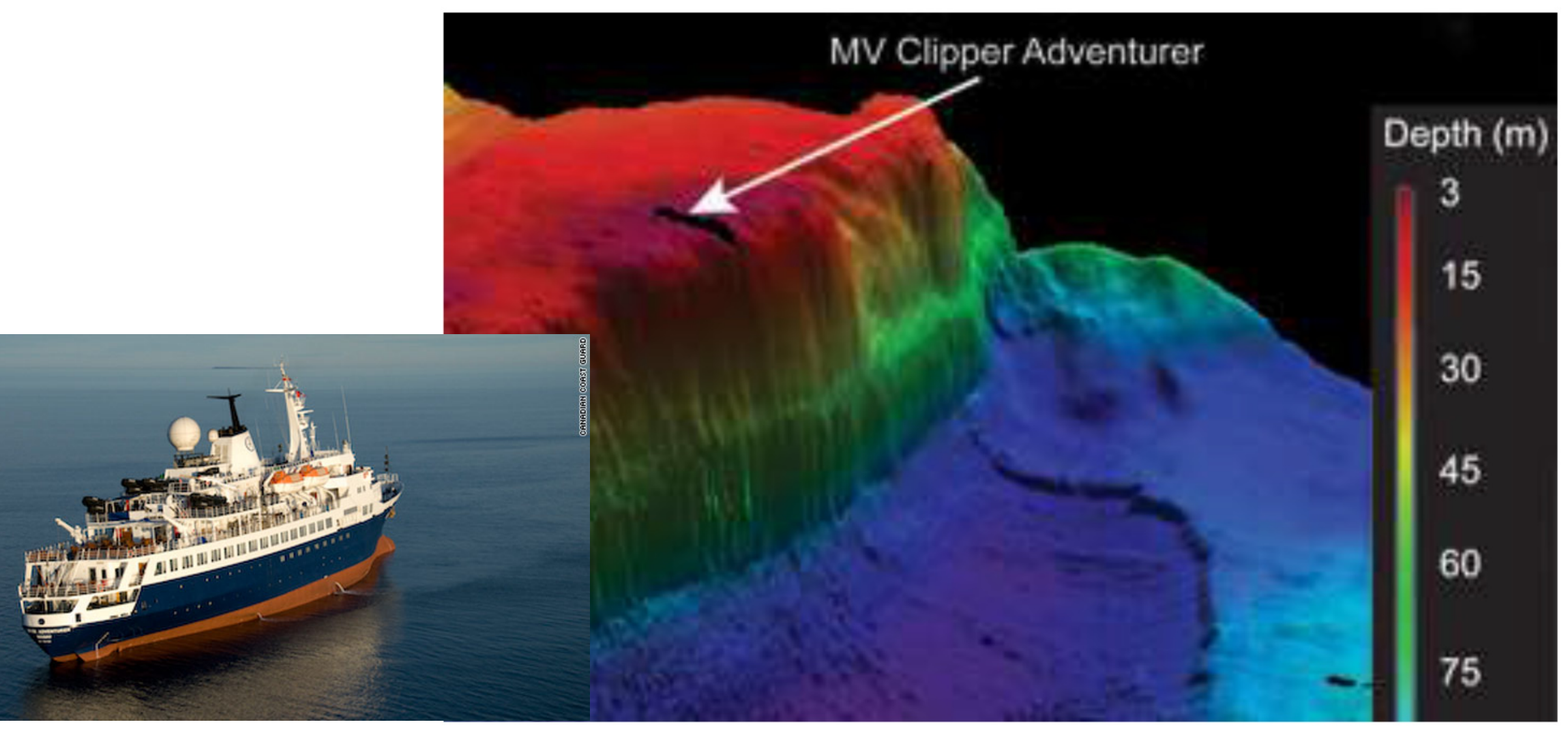

\section{M/V Clipper Adventurer Grounding on Ledge, Canada (22AUG2010)}

- FL Sonar would have provided approximately 2 minutes warning. - VAtoN placed before the ledge would have been visible on ECDIS. 


\section{Grounding Avoidance Strategies}
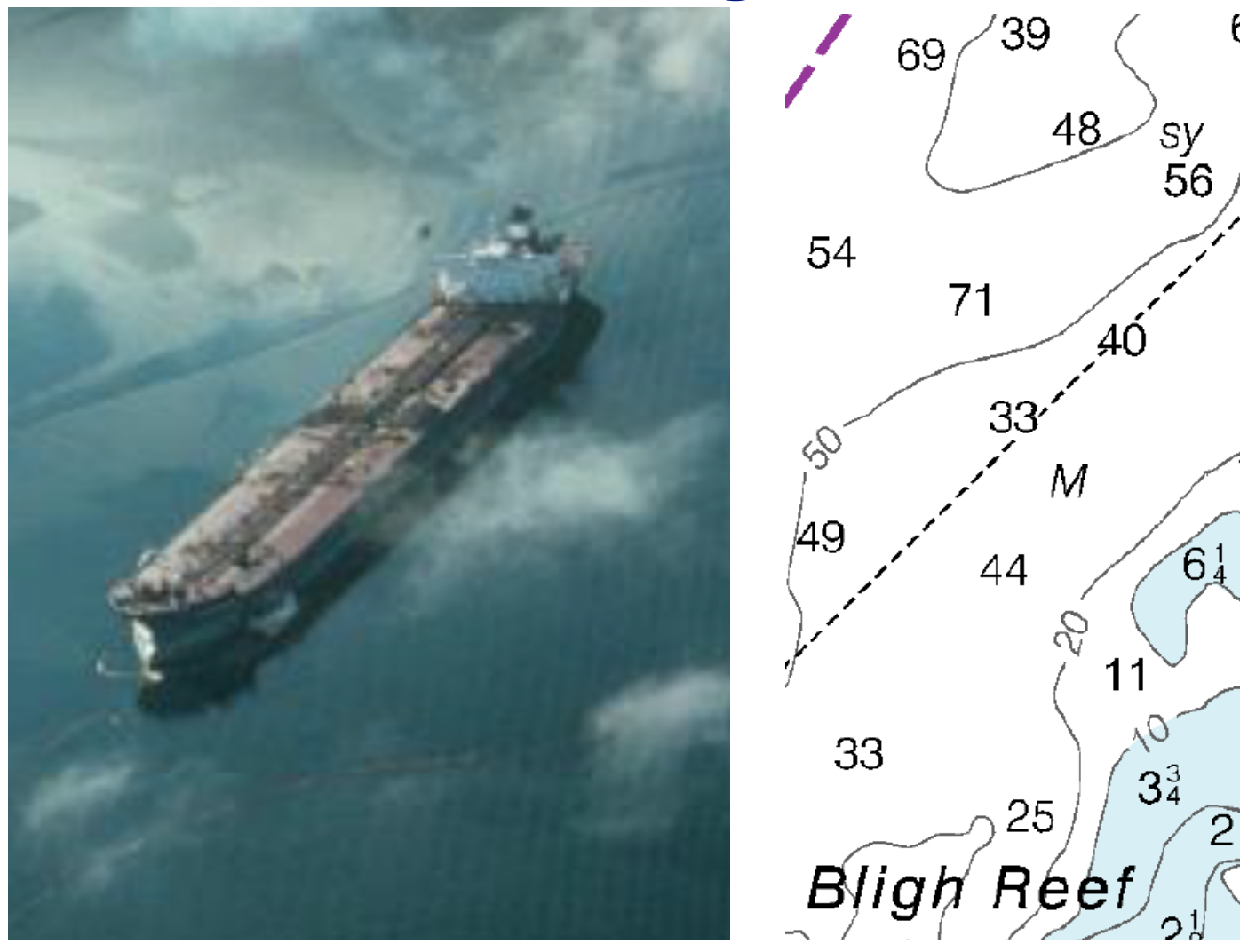

66
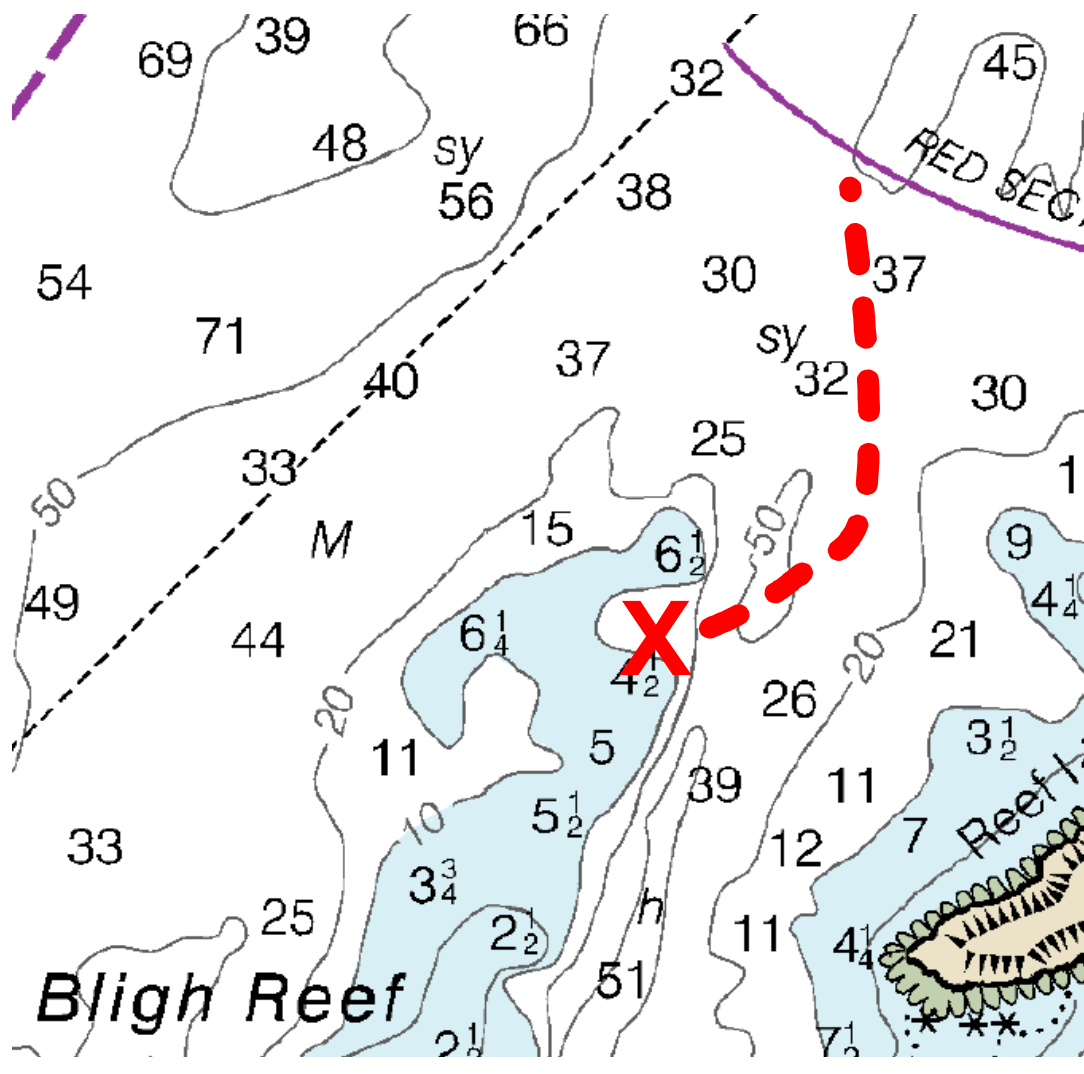

\section{M/V Exxon Valdez Grounding on Bligh Reef, USA}

(24MAR1989)

- FL Sonar would have provided approximately 3 minutes warning. - VAtoN placed before the reef would have been visible on ECDIS. 


\section{Grounding Avoidance Strategies}

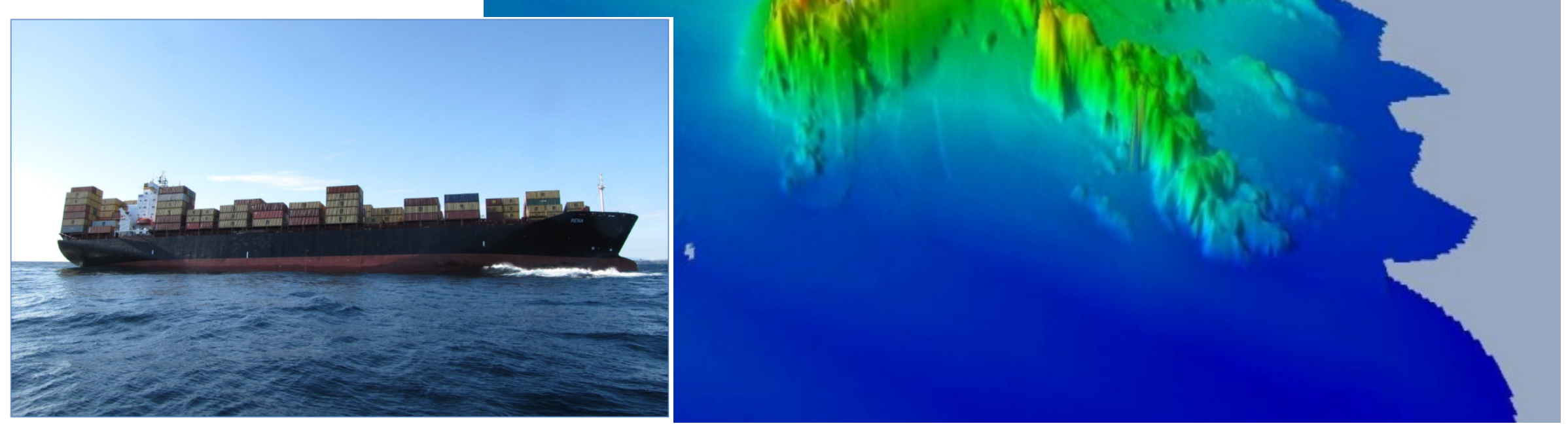

M/V Rena Grounding on Astrolabe Reef, NZ (40ст2011)

- FL Sonar would have provided approximately 2 minutes warning. - VAtoN placed before the reef would have been visible on ECDIS. 


\section{Grounding Avoidance Strategies}

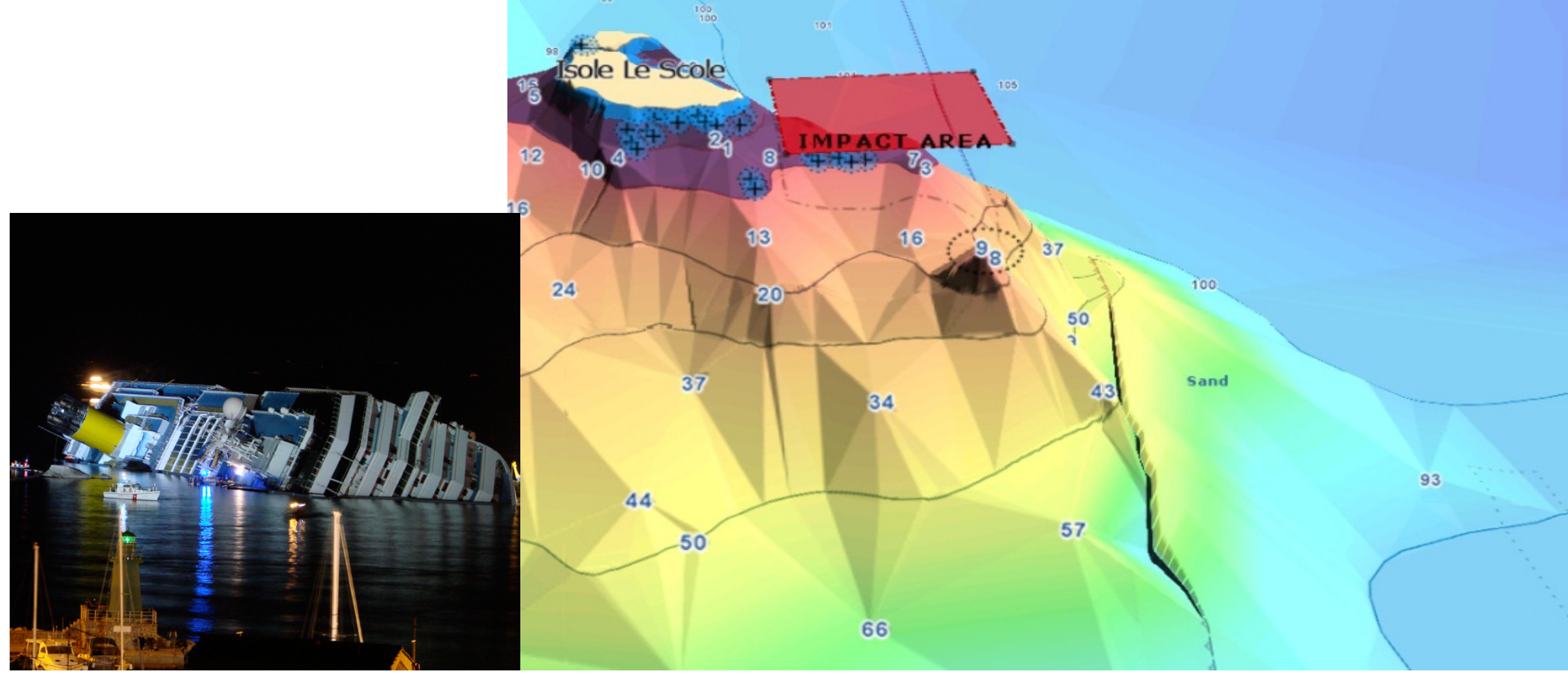

\section{M/V Costa Concordia Grounding on Scole Rocks, Italy (13JAN2012)}

- FL Sonar would have provided approximately 2 minutes warning. - VAtoN placed before the rocks would have been visible on ECDIS. 


\section{Summary / Conclusions}

- Technology provides new opportunities to increase maritime safety in poorly-charted frontiers of the Arctic.

- Forward-looking (FL) Sonar is currently available as commercial off-the-shelf equipment ready for vessel installation.

- There are currently no IMO carriage requirements for FL-Sonar, despite the advantages provided by this technology. The Polar Code should be amended to require FL-Sonar use in the Arctic.

- The IMO e-Navigation initiative should have a path for the integration of new navigation technologies beyond ECDIS and AIS.

- Crowd-sourcing FL-Sonar data to national hydrographic authorities can provide IHO Order $1 \mathrm{a} / 1 \mathrm{~b}$ survey data with full bottom coverage to supplement official resources.

- Machine-readable ENC layer containing high resolution survey data can provide an alternative method to verify both physical and virtual AtoN are "watching properly" in real time. 